\title{
Tinjauan Literatur: Faktor Penyebab dan Upaya Pencegahan Sistematis terhadap Perceraian
}

\section{Literature Review: Determinant and Systematic Prevention Measures of Divorce}

\begin{abstract}
Risa Nurhalisa* ${ }^{1}$
ABSTRAK

Latar Belakang: Angka perceraian di Indonesia pada tahun 2018 sebanyak 408.202 kasus dan meningkat sebanyak 439.002 kasus pada tahun 2019. Angka perceraian yang meningkat bertentangan dengan tujuan perkawinan karena tidak tercapainya salah satu dari fungsi keluarga dan kesehatan keluarga.

Tujuan: Artikel ini akan membahas mengenai faktor-faktor penentu perceraian dan upaya Promosi Kesehatan yang dapat dilaksanakan.

Metode: Penulisan artikel ini mengikuti komponen dari artikel lain yang sesuai untuk tinjauan sistematik dan Meta-Analisis. Penulisan tinjauan literatur dilakukan dengan cara mencari dan mengutip jurnal sistematis yang berkaitan dengan faktor penentu perceraian dan upaya pencegahan sistematik kasus perceraian. Pada awalnya, terdapat 61 artikel yang sesuai dengan kata kunci yang meliputi, faktor penentu, pencegahan sistematis, dan perceraian. Artikel diperoleh dari jurnal internasional dan jurnal nasional sebanyak 61 artikel, terdapat 41 artikel yang ditinjau dipilih berdasarkan kesesuaian dengan tujuan penulisan artikel.

Ulasan: Faktor Demografis yang menjadi pemicu perceraian yaitu ketidaksiapan untuk berumah tangga baik secara fisik dan emosional, ketidakcocokan, perselingkuhan, dan kekerasan baik secara fisik dan psikologis. Faktor Sosial-Ekonomi yang menjadi pemicu perceraian yaitu sumber daya ekonomi yang kurang serta penghasilan istri lebih besar dari pada suami. Terjadi perubahan dalam hubungan antara pendidikan wanita dan perceraian, di beberapa negara wanita berpendidikan tinggi lebih cenderung bercerai. Faktor Budaya yang terjadi di Afrika, perceraian dianggap sebagai dosa terhadap Tuhan, alam, dan masyarakat.

Kesimpulan: Faktor penentu perceraian meliputi Faktor Demografis, Faktor Sosial-Ekonomi, Faktor Pendidikan, dan Faktor Budaya. Tindakan pencegahan sistematis yang dapat dilakukan yaitu pendewasaan usia perkawinan, kelas calon pengantin atau seminar pranikah, kerjasama lintas sektor untuk pendampingan terhadap anak korban perceraian, dan lain sebagainya.
\end{abstract}

Kata kunci : faktor penentu, pencegahan sistematis, perceraian

\section{ABSTRACT}

Background: The divorce rate in Indonesia in 2018 was 408,202 cases and increased by 439,002 cases in 2019. The increasing divorce rate is contrary to the purpose of marriage because one of the family functions and family health is not achieved.

Objectives: This article will discuss the determinants of divorce and what Health Promotion efforts can take. Methods: The writing of this article follows the components of other articles suitable for systematic review and Meta-analysis. Writing a literature review is done by searching for and quoting systematic journals related to determinants of divorce and systematic prevention of divorce cases. In the beginning, 61 articles fit the keywords covering, determinants, systematic prevention, and divorce. There are 61 articles obtained from international journals and national journals, 41 articles reviewed were selected based on their suitability to write the article.

Discussions: Demographic factors that trigger divorce are physical and emotional unpreparedness for marriage, incompatibility, infidelity, and violence both physically and psychologically. Socio-economic factors that trigger divorce are fewer economic resources and the wife's income is greater than that of the husband. There have been changes in the relationship between women's education and divorce, with more educated women in some countries more likely to divorce. Cultural factors that occur in Africa, divorce is considered a sin against God, nature, and society. 
Conclusions: The determinants of divorce include demographic factors, socio-economic factors, educational factors, and cultural factors. Systematic prevention measures that can be taken are the maturity of marriage age, future bridal classes or premarital seminars, cross-sector cooperation for assistance to children who are victims of divorce, and so on.

Keywords: determinants, systematic prevention, divorce

*Koresponden :

risa.nurhalisa-2018@fkm.unair.ac.id

Risa Nurhalisa

${ }^{1}$ Departemen Promosi Kesehatan dan Ilmu Perilaku, Fakultas Kesehatan Masyarakat, Universitas Airlangga,

Kampus C Mulyorejo, 60115, Surabaya, Jawa Timur, Indonesia

\section{PENDAHULUAN}

Keluarga merupakan dua orang atau lebih yang berkomitmen satu sama lain, yang berbagi kasih sayang, nafkah, tanggung jawab pengambilan keputusan, dan nilai-nilai. Keluarga berfungsi sebagai kelompok atau sistem. Segala sesuatu yang terjadi pada anggota keluarga mana pun akan berdampak pada semua anggota keluarga yang lain (Mohammed and Yehualashet, 2016). Perceraian merupakan kulminasi dari penyelesaian perkawinan yang buruk, dan terjadi apabila antara suami-istri sudah tidak mampu lagi mencari cara penyelesaian masalah yang dapat memuaskan kedua belah pihak (Widodo, 2014).

Data statistik yang ada menunjukkan bahwa tingkat perceraian yang tinggi di sebagian besar negara Afrika. Misalnya, pada tahun 1996, terdapat 32.775 perceraian di Republik Afrika Selatan. Di Nigeria, perceraian terjadi setiap 15 menit di kalangan Muslim (Mohammed and Yehualashet, 2016). Di Lesotho antara tahun 2001 dan 2005, 1204 pernikahan dibatalkan, dan 1473 pernikahan lainnya mengajukan pembatalan dari 5.914 total pernikahan yang diselenggarakan pada tahun yang sama. Laporan pengadilan administrasi kota Gondar, pada tahun 2010 hingga 2011, sekitar 604 kasus perceraian didaftarkan, di mana 34,7\% atau 210 kasus adalah di antara umat Islam. Dari data yang diperoleh dari kantor urusan Islam kota Gondar, terdapat 401 pernikahan baru pada tahun 2010 hingga 2011 dan pada tahun yang sama sebanyak 210 kasus perceraian. Ini berarti 52,7\% dari total pernikahan berakhir dengan perceraian (Mohammed and Yehualashet, 2016).

Tingkat perceraian yang tinggi secara umum terjadi pada sebagian besar masyarakat industri telah menghasilkan banyak penelitian yang bertujuan untuk mengidentifikasi faktor-faktor penentu ketidakstabilan perkawinan (Maslauskaite et al., 2015). Faktor sosio-ekonomi perceraian telah banyak diteliti di AS dan Eropa Barat dan Utara tetapi pada tingkat yang lebih rendah di Eropa Tengah dan Timur (Amato dan James 2010; Lyngstad dan Jalovaara 2010). Amerika Serikat merupakan negara dengan angka perceraian sebanyak 776.288 kasus pada tahun 2016. Mengalami peningkatan pada tahun 2017 menjadi 787.251 kasus. Kasus perceraian pada tahun 2018 mengalami penurunan menjadi 782.038 kasus (CDC/NCHS National Vital Statistics System, 2018).

Angka perceraian di Indonesia meningkat setiap tahun nya. Angka Perceraian di Indonesia pada tahun 2015 mencapai 353.843 kasus. Angka perceraian di Indonesia pada tahun 2016 meningkat menjadi 365.654 kasus. Angka perceraian di Indonesia pada tahun 2017 meningkat menjadi 374.516 kasus. Angka perceraian di Indonesa pada tahun 2018 sebanyak 408.202 kasus. Angka perceraian di Indonesia pada tahun 2019 meningkat hingga 439.002 dengan cerai talak sebanyak 112.616 kasus dan cerai gugat sebanyak 326.386 kasus. Angka perceraian di Jawa Timur pada tahun 2017 mencapai 84.839 kasus. Angka perceraian di Jawa Timur pada tahun 2018 meningkat menjadi 88.955 kasus, sebanyak 26.790 kasus cerai talak dan sebanyak 62.165 kasus cerai gugat. Angka perceraian di Jawa Timur pada tahun 2019 mengalami peningkatan yaitu sebanyak 95.007 kasus, untuk cerai talak sebanyak 66.954 kasus, dan cerai gugat sebanyak 28.053 kasus (Badan Pusat Statistik Provinsi Jawa Timur, 2019, 2020).

Di Kota Surabaya angka perceraian mengalami peningkatan. Angka perceraian pada tahun 2018 sebanyak 5.440 kasus dengan cerai talak sebanyak 1.655 kasus dan cerai gugat sebanyak 3.785 kasus. Angka perceraian pada tahun 2019 sebanyak 6.011 kasus dengan cerai talak sebanyak 4.212 kasus dan cerai gugat sebanyak 1.799 kasus (Badan Pusat Statistik Provinsi Jawa Timur, 2019, 2020).

Lima fungsi keluarga, yang pertama fungsi afektif (The Affective Function) Fungsi ini dibutuhkan untuk perkembangan individu dan psikososial anggota keluarga. Kedua, fungsi sosialisasi berguna untuk membina sosialisasi pada anak. Ketiga, fungsi reproduksi (The Reproduction Function) adalah fungsi untuk mempertahankan generasi. Keempat, fungsi ekonomi (The Economic Function) yaitu keluarga berfungsi untuk memenuhi kebutuhan keluarga secara ekonomi, dan yang terakhir fungsi perawatan atau pemeliharaan kesehatan (The Health Care Function) salah satunya berguna untuk mempertahankan suasana rumah yang menguntungkan untuk kesehatan dan perkembangan kepribadian anggota keluarga (Friedman, 1998).

Perceraian tidak sesuai dengan fungsi keluarga, yaitu fungsi Afektif, fungsi sosialisasi, dan fungsi perawatan atau pemeliharaan kesehatan. Definisi sehat adalah suatu keadaan sejahtera yang meliputi fisik, mental dan sosial yang tidak hanya bebas dari penyakit atau kecacatan. Ketidak sesuaian fungsi keluarga 
berkaitan dengan promosi kesehatan sebagai proses yang memungkinkan individu mengendalikan dan memperbaiki kesehatannya. Upaya agar mencapai kesehatan jasmani, rohani, dan sosial yang sempurna, seseorang atau kelompok harus mampu mengidentifikasi dan mewujudkan aspirasi, mampu memenuhi kebutuhan, mampu mengubah atau beradaptasi dengan lingkungan (World Health Organization, 1986).

Tingginya angka perceraian menunjukkan bahwa terdapat persoalan-persoalan sosial yang sedang terjadi mengakibatkan pasangan suami istri mengambil jalan untuk melakukan pemutusan hubungan perkawinan atau perceraian. Perlu diketahui apa saja faktor penentu dan dampak dari perceraian karena perceraian merupakan hal yang bertentangan dengan tujuan perkawinan dimana tujuan perkawinan ialah untuk membentuk rumah tangga yang bahagia lahir dan batin untuk selama-lamanya. Berdasarkan uraian di atas, penulisan artikel ini akan membahas mengenai faktor penentu perceraian dan upaya sistematik preventif kasus perceraian.

\section{METODE}

Penulisan artikel ini mengikuti komponen dari artikel lain yang sesuai untuk tinjauan sistematik dan Meta-Analisis. Penulisan tinjauan literatur dilakukan dengan cara mencari dan mengutip jurnal sistematis yang berkaitan dengan faktor penentu perceraian dan upaya sistematik prevetif kasus perceraian. Strategi pencarian untuk faktor penyebab perceraian dan upaya pencegahan sistematis, sebagai berikut:

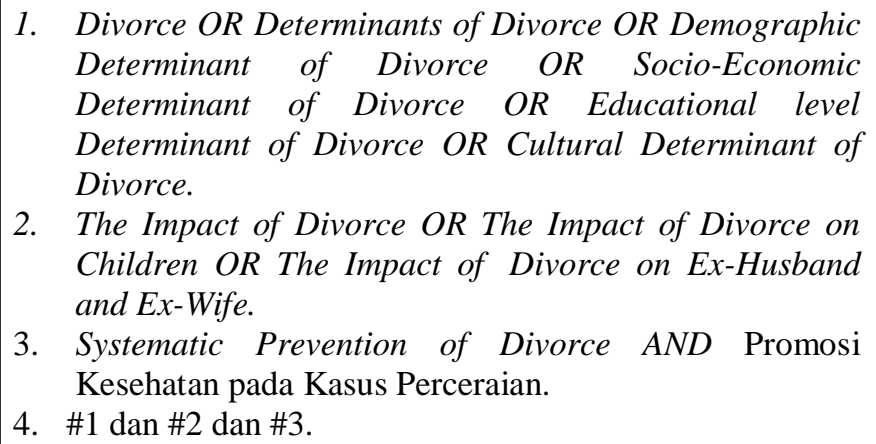

2. The Impact of Divorce OR The Impact of Divorce on Children OR The Impact of Divorce on Ex-Husband and Ex-Wife.

3. Systematic Prevention of Divorce AND Promosi Kesehatan pada Kasus Perceraian.

4. \#1 dan \#2 dan \#3.

Gambar 1. Strategi pencarian untuk faktor penyebab perceraian dan upaya pencegahan sistematis

Pada awalnya, terdapat 61 artikel yang sesuai dengan kata kunci yang meliputi, faktor penentu, pencegahan sistematis, dan perceraian. Artikel diperoleh dari dari 61 artikel, terdapat 41 artikel yang ditinjau. Pada bagian pendahuluan terdapat 3 artikel, serta 38 artikel pada hasil dan pembahasan. Artikel diperoleh dari Researchgate, Sociology, Google Scholar, Population Studies, European Sociological Review, Journal of Marriage and Family, American Sociological Association, Demographic Research, Journal of South Africa, Innovare Journal of Social Sciences, Pediatrics, Ejournal Psycology, Journal of Psicology, American Journal of Sociology, FWU Journal of Social Sciences, Journal of Divorce and Remarriage, The Business and Management Review, Jurnal IAIN Walisongo, Jurnal Universitas 'Asyiyah Yogyakarta, Jurnal UIN Syarif Hidayatullah, Jurnal Keperawatan Soedirham, Jurnal Bimas Islam, Ejurnal UNSA, Jurnal Al-Bayan, Jurnal Pendidikan Islam, dan Jurnal PG-PAUD Trunojoyo.

Kriteria kata kunci yang digunakan untuk mendapatkan referensi memiliki keterkaitan dengan topik pembahasan. Berdasarkan kriteria tersebut banyak referensi sesuai dengan paper yang telah ditemukan. Paper hanya diambil beberapa yang sesuai dengan ketentuan penulis. Pada pembahasan setiap paper, akan disusun menjadi sebuah Systematic review untuk membantu pembaca agar mengetahui faktor penentu perceraian.

\section{HASIL DAN DISKUSI}

Perceraian datang sebagai klimaks dari cerita panjang ketidakbahagiaan, dan ini memberikan jalan keluar hukum dari situasi dimana satu atau kedua pihak telah mempertimbangkannya (Mohammed and Yehualashet, 2016). Perceraian dapat disebabkan oleh keadaan ekonomi, sosial budaya, dan bio-psikologis di antara pasangan Muslim dalam pemerintahan kota Gondar (Mohammed and Yehualashet, 2016). Perceraian jauh lebih mungkin terjadi di antara pasangan dengan masalah pribadi, sosial, dan ekonomi dan didahului oleh hubungan keluarga yang bermasalah dan proses pengasuhan. Masalah psikologis, perbedaan budaya, sosial, dan keuangan dapat pula menjadi penyebab perceraian.

\section{Faktor Demografi}

Faktor-faktor demografis adalah yang menjadi pemicu perceraian yaitu usia saat menikah, persalinan pranikah dan kehamilan pranikah, hidup bersama sebelum nikah, dan riwayat perkawinan sebelumnya, dan latar 
belakang keluarga (Clarke, Lynda \& Berrington, 1998). Kasus perceraian telah meningkat secara dramatis di kalangan anak muda di Afrika Selatan, yang merupakan angka tertinggi di dunia (Oosthuizen, 2014; Bezuidenhout, 2017). Pasangan yang menikah antara usia 18 dan 35 tahun kemungkinan besar akan bercerai. Di antara 25-29 tahun, tingkat perceraian dua kali lipat lebih tinggi di antara orang-orang dalam kelompok usia yang lebih tua (Bezuidenhout, 2017; Oosthuizen, 2014).

Berbagai faktor yang saling terkait telah berkontribusi pada meningkatnya perceraian di Afrika Selatan (Makwanise, N \& Masuku, 2016). Peneliti dari Afrika Selatan mengungkapkan beberapa faktor perceraian meliputi ketidakcocokan seksual, kurangnya keintiman, kurangnya komunikasi dan lingkungan sosial, perselingkuhan dalam pernikahan (Preller, 2014; Heaton, 2014).

Kekerasan adalah salah satu kontributor utama perceraian (Preller, 2014). Kekerasan terjadi pada semua kelompok umur, kelompok etnis dan kelompok kelas, dan datang dalam berbagai bentuk, dari kekrasan dalam rumah tangga (KDRT), pelecehan fisik, pelecehan verbal, emosional, psikologis dan bahkan finansial. Kekerasan beresiko memberikan dampak terhadap anak-anak, karena anak-anak belajar dari hal yang mereka lihat. Dengan hanya menjadi saksi pelecehan antara orang tua mereka, akan beresiko memberikan dampak kepada anak tersebut.

Mengurangi peluang terjadi perceraian pada pasangan muda dapat diupayakan dengan mengenal dengan baik calon pasangan sebelum memutuskan untuk menikah, menerima konseling pra-nikah (Mohlatlole, Nkuke Evans., Sithole, Sello., \& Shirindi, Linda, 2018).

\section{Faktor Sosial-Ekonomi}

Sebesar 55\% persen wanita bercerai setiap tahun. Di Pakistan, tren perceraian meningkat karena tekanan ekonomi dan tuntutan masyarakat. Meningkatnya masalah dalam kehidupan sehari-hari membuat orang frustrasi dan tingkat kesabaran pasangan sangat rendah (Zafar and Kausar, 2014).

Sampel pasangan menikah di Amerika Serikat yang telah diamati antara tahun 1968 dan 2013, menunjukkan bahwa keadaan material, di dalam perkawinan bukanlah penentu utama stabilitas pernikahan (Killewald, 2016). Hasil dari pengamatan tersebut, terdapat keraguan hasil bahwa peningkatan tingkat perceraian pada pertengahan abad kedua puluh adalah karena meningkatnya kemandirian ekonomi perempuan. Fakta bahwa pekerjaan istri tidak dikaitkan dengan risiko perceraian, sementara kurangnya pengahasilan suami tetap terkait dengan ketidakstabilan perkawinan.

Peningkatan terjadi terhadap keluarga pencari nafkah ganda di sebagian besar negara maju barat. Di mana istri berpartisipasi dalam mencari nafkah, sedangkan penurunan dalam keluarga pencari nafkah tunggal, dimana suami adalah satu-satunya pencari nafkah. Ketidakstabilan pekerjaan atau suami yang pengangguran meningkatkan risiko perceraian, hal ini mungkin menunjuk pada peran suami yang tidak berubah sebagai pencari nafkah utama, bahkan di antara keluarga pencari nafkah ganda. Perbedaan penghasilan dimana pengahasilan istri lebih besar dari pada suami dan karena tuntutan dalam pekerjaan istri lebih banyak menghabiskan waktu untuk bekerja mengakibatkan terjadi konflik yang dapat meningkatkan resiko perceraian.Orang-orang yang mapan secara ekonomi yang memiliki sumber daya keuangan memadai, yang kedua, sejak awal pasangan tidak sesuai dengan norma yang ada seperti pernikahan dini, perbedaan usia yang terlalu jauh dengan pasangan, hamil diluar nikah, atau pernah bercerai sebelumnya (Raz-Yurovich, 2011).

\section{Faktor Pendidikan}

Hasil studi di Inggris sebelumnya telah menemukan bahwa wanita yang berpendidikan memiliki pernikahan yang lebih stabil. Prediksi setelah 15 tahun menikah, sebesar 32\% wanita yang berpendidikan rendah bercerai, dibandingkan dengan 13\% dari wanita berpendidikan tinggi yang bercerai. Di Amerika adalah salah satu negara di mana wanita berpendidikan saat ini lebih stabil dalam perkawinan dibandingkan mereka yang kurang pendidikan. Setengah abad kemudian, sebuah badan penelitian yang berkembang telah mendokumentasikan pergeseran dalam hubungan antara pendidikan wanita dan perceraian di beberapa negara Eropa dan masyarakat non-Barat. Di Amerika menyatakan, terdapat hubungan terbalik antara pendidikan wanita dan perceraian telah meluas dekade terakhir. Banyak teori mengemukakan bahwa wanita berpendidikan tinggi lebih cenderung bercerai. Di beberapa negara, wanita berpendidikan tinggi lebih sedikit melakukan pernikahan, yang berarti apabila mereka memutuskan untuk menikah lebih berkomitmen pada pernikahan mereka (Matysiak, Anna., Styrc, Marta \& Vignoli, Daniele, 2013; Hyunjoon, Park, \& Raymo, James.M, 2013; Raymo, James M., Fukuda, Setsuya \& Iwasawa, Miho, 2013).

\section{Faktor Budaya}

Perceraian dianggap sebagai keputusan yang mengubah hidup yang mana mencakup banyak cara untuk mengatasi tantangan yang mengarah pada perceraian sebelum akhirnya perceraian diputuskan secara hukum. Perceraian didasarkan pada gagasan bahwa pernikahan adalah institusi sosial. Keyakinan dan norma budaya tertentu seperti komitmen jangka panjang. Memberikan perhatian untuk anak-anak dan seorang pria sebagai pencari nafkah bagi keluarga merupakan kewajiban dari sebuah pernikahan. Ketika keyakinan dan norma-norma 
ini dilanggar, istri atau suami lebih cenderung untuk pergi karena kurangnya dukungan sosial, atau karena pasangan merasa tidak puas karena norma telah dilanggar (Sayer, LC, Englan,P, Allison,P, Kangas, 2011).

Pernikahan dianggap sebagai ikatan seumur hidup dalam masyarakat Afrika (Arugu, 2014). Secara tradisional, perceraian tidak dianggap sebagai pilihan. Anggota keluarga akan menangani perselisihan apa pun dengan menilai kasus pada kelebihannya dan menimbang semua konsekuensi dari hasilnya. Perceraian, yang pada dasarnya dianggap sebagai dosa terhadap Tuhan, alam, dan masyarakat (Arugu, 2014), hanya bisa diizinkan masuk masyarakat Afrika tradisional jika perzinaan telah dilakukan, dan terlepas dari segala upaya agar pasangan tetap bersama atau tidak bercerai. Hal tersebut merupakan sebuah keuntungan bagi pasangan datang dari latar belakang budaya yang sama, karena ini membantu mereka dalam menyesuaikan diri. Memiliki anak adalah alasan paling umum mengapa orang menikah bahwa dalam budaya Afrika, pernikahan yang tidak dikaruniai anak tidak diperhitungkan telah mencapai tujuan dari pernikahan. Diasumsikan bahwa ketika pasangan tidak dapat memiliki anak, maka tidak akan ada orang yang mengingat mereka. Garis silsilah mereka akan hilang. Apalagi dalam beberapa budaya seorang wanita yang melahirkan khusus anak perempuan dapat bercerai, karena anak perempuan tidak bisa lanjutkan dengan nama keluarga ayah (Bezuidenhout, 2017).

\section{Promosi Kesehatan dalam Perceraian}

Perceraian mempunyai pengaruh yang sangat besar terhadap perkembangan jiwa dan pendidikan anak, terutama anak usia sekolah dasar dan remaja. Diantaranya dapat menyebabkan anak bersikap pendiam dan rendah diri, nakal yang berlebihan, prestasi belajar rendah dan merasa kehilangan (Arugu, 2014). Akibat psikologis perceraian selalu berakibat buruk bagi anak-anak dan ini dapat memberikan perasaan sedih serta takut pada diri anak. Upaya dalam menjamin kelangsungan masa depan anak korban perceraian, maka beberapa agenda kebijakan yang dapat dilakukan antara lain yang pertama, memantau kelanjutan Pendidikan berupa Program beasiswa dan pendampingan khusus. Kedua, penguatan diri untuk pembangunan karakter dan Motivasi Hidup. Diperlukan kerjasama lintas sektor seperti Dinas Pendidikan, Perguruan Tinggi, Dinas Sosial, BKKBN, serta LSM (Ningrum, Putri Rosalia, 2013; Yusuf, M, 2014; Yasyakur, 2015).

Keluarga yang stabil dan berfungsi baik, terdiri dari 2 orang tua beserta anak, berpotensi aman dan mendukung lingkungan pola asuh yang optimal untuk tumbuh kembang anak. Keluarga menjalankan 2 fungsi utama, yaitu merawat dan memberikan pengasuhan pada anak-anak dan merupakan tempat nilai diajarkan dan dipelajari. Dampak perceraian pada ibu cenderung bereaksi dengan mengonsumsi lebih banyak alkohol, lebih banyak memanfaatkan layanan kesehatan untuk mengatasi depresi, kecemasan, atau perasaan terhina, dan merasa kurang mampu berperan sebagai orang tua. Dampak yang terjadi pada ayah merasa dikesampingkan, kurang diterima oleh anak-anaknya, dan juga bisa menderita depresi, cemas, dan penyalahgunaan narkotika. Kualitas hubungan kakek dan nenek dengan cucu-cucu mereka juga sering menurun. Tindakan sistematis preventif perceraian yang pertama, memperkuat dasar kepribadian orang dewasa yang siap memasuki atau menjalani pernikahan berupa promosi kesehatan pernikahan contohnya pembekalan atau seminar pranikah. Kedua, memperkuat dasar kepribadian orang dewasa yang sudah siap menikah mengenai resiko dan pencegahan penyakit. Ketiga, membantu pasangan suami istri mengenali secara dini dan memilih tindakan pencegahan atau penghilangan risiko ketidakharmonisan dalam pernikahan. Keempat, melakukan mediasi keluarga ketika terdapat permasalahan dalam hubungan suami istri, yakni ketika suami istri sendiri tidak mampu mengatasi ketidakharmonisan keluarganya. Kelima, melakukan pendampingan rehabilitatif pada suami istri yang sudah putus perceraiannya secara hukum, untuk meminimalisir dampak buruk perceraian pada pasangan itu sendiri, dampak bagi anak, dan dampak bagi keluarga pasangan, terutama untuk pendampingan pengasuhan anak paska perceraian. Orang tua dapat membantu menyiapkan anak-anak mereka mengenai apa yang terjadi. Penyiapan harus sesuai usia dan tingkat perkembangan si anak. Orang tua harus menunjukkan komitmen kuat untuk bekerja sama dalam pengasuhan anak walaupun sudah berpisah (Ningrum, Putri Rosalia, 2013; Yusuf, M, 2014; Yasyakur, 2015).

Pernikahan dini pada dasarnya berdampak pada segi fisik maupun biologis remaja. Adanya konflik yang berujung perceraian, serta keadaan kesehatan reproduksi seperti kanker serviks, infeksi menular seksual, selain itu juga berdampak pada kematian bayi dan ibu, yang dikarenakan keadaan organ reproduksi yang kurang siap (BKKBN, 2010 ; Sabi, 2012 ; Atoillah, 2016; Dita, 2016; Setiowati, 2014; Pemerintah Kota Surabaya, 2017). Pernikahan dini di Kecamatan Sukowono adalah melalui Pendewasaan Usia Perkawinan (PUP). PUP adalah upaya untuk meningkatkan usia perkawinan pertama, sehingga pada saat perkawinan mencapai usia minimal 20 tahun bagi perempuan dan 25 tahun bagi laki-laki. PUP bukan sekedar menunda perkawinan sampai usia tertentu saja, akan tetapi juga mengusahakan agar kehamilan pertama terjadi pada usia yang cukup dewasa. PUP sangat penting bagi generasi muda agar dapat mempersiapkan pernikahan dengan penuh perencanaan.

Upaya meningkatkan bekal dalam membangun rumah tangga melalui kelas catin atau kelas calon pengantin. Setiap calon pengantin wajib mengikuti kegiatan ini untuk mendapatkan syarat administrasi dalam mendaftarkan pernikahan. Tujuan kelas calon pengantin adalah untuk meningkatkan keharmonisan dalam rumah tangga sehingga mengurangi kemungkinan terjadinya perceraian. Kelas catin yang dilaksanakan juga memberikan konseling pranikah oleh seseorang yang professional kepada pasangan calon suami istri. Salah satu kegiatan dalam kelas catin adalah penyuluhan kesehatan reproduksi. Penyuluhan dilaksanakan oleh tenaga 
kesehatan yang kompeten serta menguasai materi kesehatan reproduksi (Aminah, 2016; Arruum, R. L., T. F, Sahidah, dan Z, Febriani, 2016; Sugandhi, 2011; Sururun, dan Muslim, 2014; Fatmawati, 2010; Hapipah, 2013).

Tabel. 1 Faktor Penyebab Peceraian dan Pencegahan Sistematis

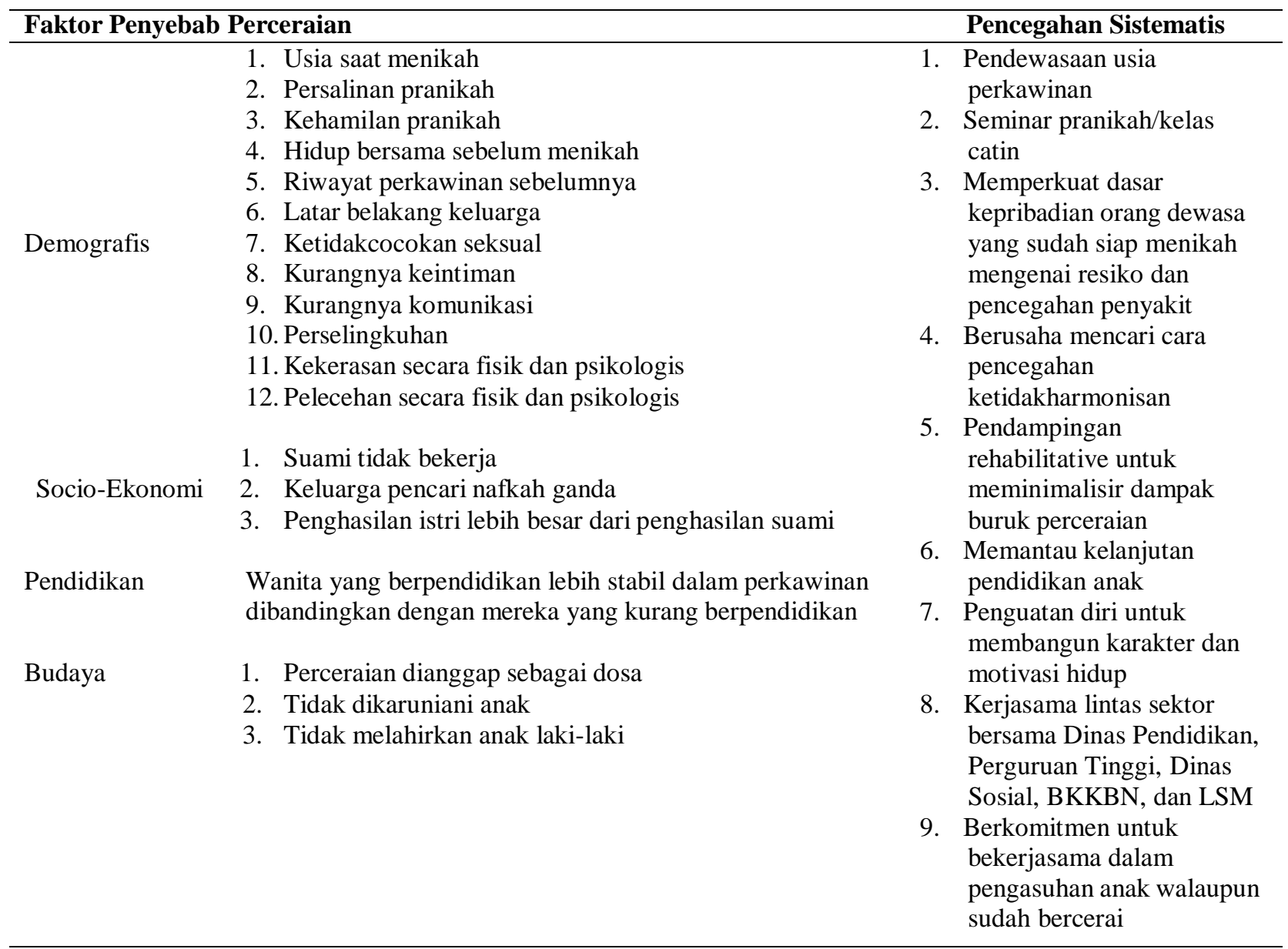

\section{KESIMPULAN}

Faktor-faktor penentu terjadinya perceraian yaitu faktor demografis, faktor sosial-ekonomi, faktor budaya, dan faktor pendidikan. Dampak perceraian akan dirasakan oleh anak dan pasangan suami istri yang bercerai. Tindakan pencegahan sistematis yang dapat dilakukan dalam menangani kasus perceraian yaitu Pendewasaan Usia Perkawinan (PUP), Kelas Calon Pengantin atau Seminar Pranikah yang mencakup pendidikan reproduksi, dan melakukan pendampingan rehabilitatif pada suami istri yang sudah putus perceraiannya secara hukum. Upaya untuk meminimalisir dampak buruk perceraian pada pasangan itu sendiri, dampak bagi anak, dan dampak bagi keluarga pasangan, kerjasama lintas sektor untuk pendampingan terhadap anak korban perceraian, dan orang tua harus menunjukkan komitmen kuat untuk bekerja sama dalam pengasuhan anak walaupun sudah berpisah. 


\section{REFERENSI}

Aminah, U. (2016) 'Analisis Terhadap Program Kursus Calon Pengantin (Suscatin) dalam Menekan Angka Perceraian', Jurnal. IAIN Sultan Maulana Hasanuddin:Banten.

Arruum, R. L., T. F, Sahidah, dan Z, Febriani (2016) 'Peningkatan Optimisme dan Pengetahuan Mengenai Pernikahan Pada Calon Pengantin Melalui Program Pelatihan Persiapan Pra Nikah', Prosiding SNaPP: Kesehatan (Kedokteran, Kebidanan, Keperawatan, Farmasi dan Psikologi), 2(1)

Arugu, L. (2014) 'Social Indicators and Effects of Marriage Divorce in African Societies', The Business \& Management Review, 4(4), pp. 374-383. Available at: https://pdfs.semanticscholar.org/7bfb/63ffee6a32d5cefd3b169be56664bf478355.pdf?_ga=2.1408501 62

$.1778691904 .1591622916-1081171785.1591535718$.

Atoillah, I. (2016) 'Pemeriksaan Kesehatan Pra Nikah dalam Perspektif Hukum Islam (Studi KUA Jetis Kota Yogyakarta tahun 2011)', Jurnal Universitas Islam Negeri Sunan Kalijaga: Yogyakarta.

Badan Pusat Statistik Indonesia (2018) STATISTIK INDONESIA 2018.

Badan Pusat Statistik Indonesia (2020) STATISTIK INDONESIA 2020.

Badan Pusat Statistik Provinsi Jawa Timur (2019) PROVINSI JAWA TIMUR DALAM ANGKA 2019.

Badan Pusat Statistik Provinsi Jawa Timur (2020) PROVINSI JAWA TIMUR DALAM ANGKA 2020.

Bezuidenhout, F. J. (2017) A Reader on Selected Social Issues. 5th edn. Pretoria: Van Schaik.

BKKBN (2010) Pendewasaan Usia Perkawinan dan Hak-Hak Reproduksi bagi Remaja Indonesia. 2nd edn. Jakarta: BKKBN.

CDC/NCHS National Vital Statistics System (2018) Provisional Number of Divorces and Annulments and Rate: United States 2000-2018, 2019.

Dita, R. H. (2016) 'Hubungan Tingkat Pengetahuan Tentang Kesehatan Reproduksi dengan Kesiapan Menikah pada Calon Pengantin di KUA Umbulharjo Yogyakarta Tahun 2016', Jurnal. Universitas 'Aisyiyah Yogyakarta.

Friedman, J. (1998) Family nursing: Theory and Practice. 3rd edn. California: Appleton \& Lange.

Hapipah (2013) 'Peran Bimbingan Pra Nikah Bagi Calon Pengantin di Kantor Urusan Agama (KUA) Kecamatan Ciputat Kota Tanggerang Selatan', Jurnal UIN Syarif Hidayatullah.

Heaton, J. (2014) The Law of Divorce and Dissolution of Life Partnership in South Africa. Cape Town:Juta and Company.

Hyunjoon, Park, \& Raymo, James.M (2013) 'Divorce in Korea: Trends and Educational Differentials',

Journal of Marriage and Family, 75(1), pp. 110-126. doi: 10.1111/j.1741-3737.2012.01024.x.

Killewald, A. (2016) 'Money, Work, and Marital Stability: Assessing Change in the Gendered Determinants of Divorce', American Sociological Association, 81(4), pp. 696-719. doi: 10.1177/0003122416655340.

Makwanise, N \& Masuku, M. (2016) 'African Traditional Views on Divorce: A Case of the Ndebele in the Vukuzenzele Ward at Esikhoveni, Esigodini, Oral History’, Journal of South Africa, 4(1), pp. 123-

128. Available at: https://upjournals.co.za/index.p

hp/OHJSA/article/view/624.

Maslauskaite, A. et al. (2015) 'Socio-economic determinants of divorce in Lithuania: Evidence from registerbased census-linked data', Demographic Research, 33(1), pp. 871-908. doi: 10.4054/DemRes.2015.33.30.

Matysiak, Anna., Styrc, Marta \& Vignoli, Daniele (2013) 'The Changing Educational Gradient in Marital Disruption: A Meta-analysis of European Research Findings', Population Studies, 68(2), pp. 197215. Available

at: https://www.researchgate.net/publication/241760562_The_changing_educational_gradient_in_marit al_disruption_A_meta-analysis_of_European_longitudinal_research.

Mohammed, S. J. and Yehualashet, Y. W. (2016) 'Determinants of Divorce in Muslim Community in Gondar City Administration', Innovare journal of social Sciences, 4(4), pp. 2-7.

Mohlatlole, Nkuke Evans., Sithole, Sello., \& Shirindi, Linda (2018) 'Factors contributing to divorce among young couples in Lebowakgomo', Social Work/Maatskaplike Werk, 54(2). doi: 10.15270/54-2- 637.

Ningrum, Putri Rosalia (2013) 'Perceraian Orang Tua Dan Penyesuaian Diri Remaja (Studi Pada Remaja Sekolah Menengah Atas/Kejuruan Di Kota Samarinda)', eJournal Psikologi, 1(1), pp. 69-79. Available at: ejournal.psikologi.fisip-unmul.or.

Oosthuizen, R. (2014) 'Divorce in South Africa: What are the reasons for divorce in South Africa', SA Journal of Psychology, 40(74), pp. 1190-1198.

Pemerintah Kota Surabaya (2017) Instruksi Walikota Surabaya Nomor 1 Tahun 2017 tentang Pelaksanaan Pemeriksaan Kesehatan dan Penyuluhan Kesehatan Reproduksi

Calon Pengantin.

Preller, B. (2014) Everyone's Guide to Divorce and Separation. Cape Town, South Africa: Zebra Press.

Raymo, James M., Fukuda, Setsuya \& Iwasawa, Miho (2013) 'Educational Differences in Divorce in Japan', Demographic Research, 28(6), pp. 177-206. Available at https://www.demographicresearch.org/volumes/vol28/6/28-6.pdf. 
Raz-Yurovich, L. (2011) 'Economic Determinants of Divorce Among Dual-Earner Couples: Jews in Israel', Demographic Research, 28(2), pp. 177-203. doi: 10.1007/s10680-012-9256-3.

Sabi, Y. (2012) Gambaran Status Kesehatan dan Faktor Penyebab Pernikahan Usia Dini pada Remajadi Desa Cio Gerong Kabupaten Pulau Morotai Maluku Utara. Available at: http://repository.library.uksw.edu/.

Sayer, LC, Englan,P, Allison,P, Kangas, N. (2011) 'She left, He left: How Employment and Satisfaction Affect Men's and Women's Decisions to Leave Marriages', American Journal of Sociology, 116(6), pp. 1982-2018. Available at: 6 Tahun', Jurnal PG-PAUD Trunojoyo, 2, pp. 76-149.

Widodo (2014) 'Faktor-Faktor serta Alasan yang Menyebabkan Tingginya Angka Cerai Gugat',

Ejournal UNSA, 8(2).

World Health Organization (1986) The Ottawa Charter for Health Promotion, WHO. Available at: https://www.who.int/healthpromotion/conferences/previous/ottawa/en/index1.html (Accessed: 16 May 2020).

Yasyakur, M. (2015) 'Dampak Perceraian Orang Tua Terhadap Prestasi Anak (Studi Kasus Di Kecamatan Nanggung, Bogor)', Edukasi Islami Jurnal Pendidikan Islam, 4.

Yusuf, M, M. (2014) 'Dampak Perceraian Orang Tua Terhadap Anak', Jurnal Al-Bayan, 20(29).

Zafar, N. and Kausar, R. (2014) 'Emotional and Social Problems in Divorced and Married Women', $F W U$
Journal of Social Sciences, 8(1),
pp.
31-35. Available at: http://ezproxy.fiu.edu/login?url=https://searchproquest.com.ezproxy.fiu.edu/docview/1676467655 ?accountid=10901. 